\title{
Renal Bicarbonate Reabsorption in the Rat \\ II. Distal Tubule Load Dependence and Effect of Hypokalemia
}

\author{
G. Capasso, P. Jaeger, G. Giebisch, V. Guckian, and G. Malnic \\ Department of Physiology, Yale University School of Medicine, New Haven, Connecticut 06510
}

\begin{abstract}
We studied two groups of rats acutely loaded with bicarbonate, control rats on a standard diet and rats kept on a $\mathrm{K}$-free diet for 3 wk. Compared with controls, K-depleted rats had reduced fractional excretion of bicarbonate despite their elevated filtered bicarbonate load. Distal bicarbonate reabsorption increased in K-depleted rats. In the presence of almost identical early distal bicarbonate loads (481 $\pm 40 \mathrm{pmol} / \mathrm{min}$ in controls and $444 \pm 50$ $\mathrm{pmol} / \mathrm{min}$ in $\mathrm{K}$ depletion), distal bicarbonate reabsorption was significantly enhanced in $K$ depletion $(247 \pm 17 \mathrm{pmol} / \mathrm{min})$ as compared with controls $(179 \pm 18 \mathrm{pmol} / \mathrm{min})$. These values are significantly different from each other, and both are severalfold higher than bicarbonate reabsorption in nonloaded conditions. In conclusion, (a) distal bicarbonate reabsorption is load dependent, and (b) distal bicarbonate reabsorption is stimulated in $K$ depletion.
\end{abstract}

\section{Introduction}

In a previous study we had demonstrated significant rates of net bicarbonate reabsorption along superficial distal tubules of rats in normal acid-base conditions (1). Significant bicarbonate reabsorption persisted during states of hypokalemia, a condition that also led to the establishment of steeper transepithelial concentration gradients of bicarbonate. However, the reduced delivery of bicarbonate ions to the early distal tubule during hypokalemia made difficult a meaningful comparison with control transport rates of bicarbonate.

In the present study, we have investigated bicarbonate transport along the distal tubule after administration of an exogenous bicarbonate load. This maneuver serves two purposes. First, it allows for testing of load dependence of bicarbonate reabsorption in normal acid-base conditions. This is of interest because in some recent microperfusion studies of distal tubules of control rats imposition of an increased bicarbonate load produced neither bicarbonate transport nor transport stimulation $(2,3)$. Second, we adjusted the early distal bicarbonate load in our experiments so that comparable amounts of bicarbonate were delivered to the early distal tubule of both control and hypokalemic

Part of this material has appeared in abstract form (1986. Kidney Int. 29:365).

Present addresses: G. Capasso, Nuovo Policlinico, Padiglione 17, Via Pansini, 80100 Napoli, Italy; P. Jaeger, Departement de Medecine, Universite de Lausanne, CHUV, Lausanne, Switzerland; and G. Malnic, Departamento de Fisiologia, Universidade de Sao Paulo, Instituto de Ciencias Biomedicas, Caixa Postal 4365, 01000 Sao Paulo, Brazil.

Received for publication 18 November 1986.

J. Clin. Invest.

(C) The American Society for Clinical Investigation, Inc.

$0021-9738 / 87 / 08 / 0409 / 06 \quad \$ 2.00$

Volume 80, August 1987, 409-414 rats. This made it possible to observe directly the effects of hypokalemia on distal bicarbonate transport.

Our studies indicate significant enhancement of distal bicarbonate transport in control animals exposed to an augmentation of the distal bicarbonate load. We also observed that at comparable early distal bicarbonate loads, hypokalemia exerted a powerful stimulation of distal bicarbonate reabsorption.

\section{Methods}

Preparation of animals. The general experimental procedure closely followed that described in a previous paper from our laboratory (1). We used male Sprague-Dawley rats (Charles River Breeding Laboratories, Inc., Wilmington, MA) kept in group cages, fasted overnight, but given free access to water until the time of the experiment. Animals were anesthetized intraperitoneally with Inactin (Promonta, FRG) using a dose of $120 \mathrm{mg} / \mathrm{kg}$ body wt, tracheostomized, and placed on a thermoregulated table designed to hold body temperature at $37^{\circ} \mathrm{C}$. The right carotid artery was catheterized for blood pressure monitoring, and periodic blood samples were taken for the measurement of hematocrit, radioactive inulin, $\mathrm{pH}$, and total $\mathrm{CO}_{2}$. The left jugular vein was cannulated and used for infusion of loading solution via a syringe pump (Harvard Apparatus Co. Inc., S. Natick, MA). The left kidney was exposed through a flank incision, decapsulated, and immobilized in a lucite chamber. The kidney was bathed with prewarmed $\left(37^{\circ} \mathrm{C}\right)$ paraffin oil. The left ureter was catheterized for collection of urine.

Two groups of rats were studied, $(a)$ control rats maintained on a standard Purina rat lab chow diet, and $(b)$ rats maintained on a lowpotassium diet (No. 170550; Teklad, Madison, WI) for 3-5 wk before the experiment.

After completion of surgery, all rats received a priming injection of $100 \mu \mathrm{Ci}$ methoxy- $\left[{ }^{3} \mathrm{H}\right]$ inulin (New England Nuclear, Boston, MA) followed by a sustaining infusion that delivered $\left[{ }^{3} \mathrm{H}\right]$ inulin at a rate of 110 $\mu \mathrm{Ci} / \mathrm{h}$. Control animals received a solution containing $260 \mathrm{mM} \mathrm{NaHCO}_{3}$ and $30 \mathrm{mM} \mathrm{KHCO}$ at a rate of $4.6 \mathrm{ml} / \mathrm{h}$; the low-K animals received a solution containing $300 \mathrm{mM} \mathrm{NaHCO}$ at the same rate.

Micropuncture. Collections of tubule fluid samples were started in both groups after a 1-h equilibration period. We used freeflow micropuncture techniques published in previous work from this laboratory (1). Early and late distal tubule segments were identified with the injection of $20 \mu \mathrm{l}$ i.v. food, drugs, and cosmetics solution (5\% FD \& C green dye No. 1, pH 7.4). Puncture sites were identified by filling the tubule with a microfil silicone rubber compound (Canton Biomedical Products, Boulder, $\mathrm{CO}$ ). The kidneys were then macerated overnight in $25 \% \mathrm{NaOH}$ and the puncture sites determined by microdissection. Puncture sites were divided into early distal (between 20 and $40 \%$ distal tubule length) and late distal (60-95\% distal tubule length) collection sites.

Analytical methods. Tubule fluid total $\mathrm{CO}_{2}$ concentration was determined by microcalorimetry (Picapnotherm; World Precision Instruments, Inc., New Haven, CT) immediately after collections and used to assess bicarbonate concentrations. The procedure described in a previous paper was carefully followed (1). The blood acid-base status was assessed using a gas analyzer (model 213-329, Instrumentation Laboratory, Inc., Lexington, MA). Total plasma $\mathrm{CO}_{2}$ was determined using a carbon dioxide analyzer (model 960; Corning Medical Glass Works, Medfield, MA). $\left[{ }^{3} \mathrm{H}\right]$ Inulin radioactivity was measured in a liquid scintillation spectrometer (model 92; Searle, Chicago, IL) in Hydrofluor (New England Nu- 
clear). Urine volumes were estimated gravimetrically. The volumes of collected tubule fluid samples were measured in a calibrated constant bore capillary. Plasma potassium was determined by standard flame photometry.

Calculations. Inulin clearance (GFR) ${ }^{1}$ and fractional bicarbonate excretion rates were determined using standard formulae, as were single nephron GFR and fractional bicarbonate delivery. All data are expressed as mean \pm SEM. Student's $t$ test was used for paired or unpaired data, as appropriate, to evaluate the significance of differences. Regression lines were obtained by the least squares method, and the significance of the slopes was calculated by analysis of variance. Correlation coefficients $(r)$ were also calculated for the variation of data with tubular length.

\section{Results}

Table I provides a summary of data on body weight, blood and urine electrolytes, systemic acid-base parameters, and GFR in bicarbonate-loaded control and potassium-depleted rats. As expected, plasma potassium was markedly depressed in rats maintained on a low-K diet, whereas plasma bicarbonate was significantly increased. The fractional excretion of bicarbonate was significantly lower in the $\mathrm{K}$-depleted rats $(P<0.05)$. Blood $\mathrm{pH}$, $\mathrm{PCO}_{2}$, and $\left[\mathrm{HCO}_{3}^{-}\right]$data on Table I were obtained from blood samples drawn at the end of the experiment. Bicarbonate concentrations however were measured approximately every halfhour in all experiments; mean values of $36.2 \pm 0.7 \mathrm{mM}$ were obtained in control bicarbonate-loaded rats, and $47.2 \pm 0.9 \mathrm{mM}$ in low-K rats. These values were used to calculate fractional reabsorption along the nephron.

Figs. 1 and 2 summarize micropuncture data on the progress of tubular fluid/plasma (TF/P) inulin concentration ratios along the distal tubule in control and low-K rats. The equation of the regression line for control conditions (Fig. 1) is $y=1.32+0.092 x$ $(n=21 ; r=0.86)$ where $y=\mathrm{TF} / \mathrm{P}$ In and $x$-localization in percent. Comparable values for low-K rats are $y=1.048$ $+0.095 x(n=17 ; r=0.93)$. Thus, to the same extent, significant fluid reabsorption along the distal tubule occurred in both groups of rats.

Figs. 3 and 4 show the progress of total $\mathrm{CO}_{2}$ concentration ratios along the superficial distal tubules of control and low-K animals. Equations of the regression lines are $y=1.40+0.0042 x$ $(n=21 ; r=0.27)$ for control and $y=1.047+0.0013 x(n$ $=17 ; r=0.23$ ) in low-K rats. Note that despite the presence of higher plasma bicarbonate concentration in the low-K group, the TF/P bicarbonate was significantly $(P<0.005)$ lower in $\mathrm{K}$ deficient rats (TF/P intercept, 1.047) compared with control rats (TF/P intercept, 1.40).

Figs. 5 and 6 provide data on fractional bicarbonate reabsorption of control and low-K rats. Significant bicarbonate reabsorption took place along the superficial distal tubule of both groups of rats. Regression equations: control, $y=0.411$ $-0.0025 x(n=21 ; r=0.78)$; low K, $y=0.335-0.0027 x$, $(n$ $=17 ; r=0.84)$.

Fig. 7 and Table II summarize mean TF/P inulin, TF/P bicarbonate, and TF/P bicarbonate/inulin concentration ratios in control and $\mathrm{K}$-depleted rats. Values obtained from early distal tubules (between 20 and 40\% distal tubular length) and late distal tubules (60-95\% distal tubular length) are compared. The dis-

1. Abbreviations used in this paper: GFR, inulin clearance; TF/P, tubule fluid/plasma concentration ratio.
Table I. Data on Body Weight, Plasma Composition, GFR, and Urinary Excretion in Control and Low-K Rats

\begin{tabular}{|c|c|c|c|}
\hline & Control rats & Low-K rats & $P$ \\
\hline Body weight $(g)$ & $254.00 \pm 18.00$ & $257.00 \pm 8.00$ & NS \\
\hline \multicolumn{4}{|l|}{ Plasma K } \\
\hline (meq/liter) & $3.70 \pm 0.01$ & $1.60 \pm 0.03$ & $<0.001$ \\
\hline \multicolumn{4}{|l|}{ 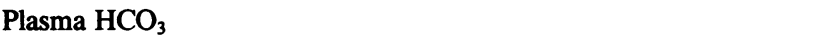 } \\
\hline$(m M)$ & $38.50 \pm 2.49$ & $46.00 \pm 5.00$ & $<0.001$ \\
\hline Blood pH & $7.65 \pm 0.04$ & $7.71 \pm 0.02$ & NS \\
\hline \multicolumn{4}{|l|}{ Blood $\mathrm{PCO}_{2}$} \\
\hline$(m m H g)$ & $36.90 \pm 0.09$ & $37.00 \pm 0.35$ & NS \\
\hline HCT (\%) & $45.00 \pm 1.40$ & $48.00 \pm 0.70$ & NS \\
\hline \multicolumn{4}{|l|}{ GFR ( $\mathrm{ml} / \mathrm{min} \mathrm{per}$} \\
\hline kidney) & $1.42 \pm 0.21$ & $1.23 \pm 0.12$ & NS \\
\hline \multicolumn{4}{|l|}{ Urine/plasma } \\
\hline inulin & $102.00 \pm 16.00$ & $77.80 \pm 35.00$ & NS \\
\hline $\mathrm{FE} \mathrm{HCO}_{3}(\%)$ & $9.20 \pm 0.50$ & $5.90 \pm 2.00$ & $<0.05$ \\
\hline
\end{tabular}

HCT, hematocrit; FE, fractional excretion.

tribution of the localizations of puncture sites, expressed as percent of distal tubular length, were $36.3 \pm 3.7(n=6)$ in control and $32.7 \pm 2.4(n=6)$ in low-K rats for early distal puncture sites. For late distal tubules, the corresponding values were 83.7 $\pm 2.7(n=15)$ in control rats and 81.3 $\pm 2.6(n=11)$ in low$K$ rats. Both in early and late distal collection sites, TF/P inulin ratios were similar in control and low-K rats. Likewise, early distal flow rates were $8.64 \pm 1.16(n=6) \mathrm{nl} / \mathrm{min}$ in control rats and $8.54 \pm 1.13(n=6) \mathrm{nl} / \mathrm{min}$ in low-K rats; these values were not significantly different. On the other hand, the TF/P bicarbonate ratios in early and late distal tubule were significantly lower in the low-K rats $(P<0.005)$.

A summary of fractional bicarbonate deliveries to various tubule sites is also given in Table II and Fig. 4. We note that, compared with control values, smaller fractions of total bicarbonate are present in the early and late distal tubule of low-K rats. Importantly, the difference between early and late distal bicarbonate deliveries is significant both in control and K-depleted rats. We conclude that significant bicarbonate reabsorption occurs along the distal tubule in both experimental conditions.

Fig. 8 provides a schematic overview of absolute bicarbonate reabsorption rates along the distal tubule during bicarbonate loading in control and hypokalemic conditions. Previous results from this laboratory obtained in similar groups of rats without bicarbonate loading are included for comparison (1). In the present set of experiments we found that the filtered bicarbonate load was higher $(P<0.01)$ in low-K rats $(1,763 \pm 85 \mathrm{pmol} / \mathrm{min})$ than in control rats $(1,532 \pm 45 \mathrm{pmol} / \mathrm{min})$, despite the fact the single nephron glomerular filtration rate, as measured at distal tubule levels, was significantly $(P<0.05)$ reduced in hypokalemia

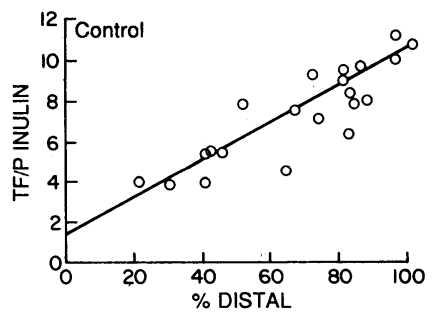

Figure 1. Inulin TF/P concentration ratios along distal tubules in control bicarbonateloaded rats. The regression lines of the data are included (see text). The increase in inulin TF/P ratios with tubule length is highly significant $(P$ $<0.01$ ). 


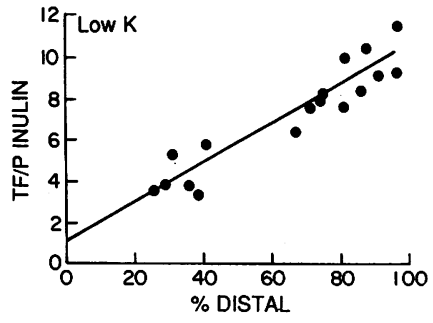

Figure 2. Inulin TF/P concentration ratios along distal tubules in low-K bicarbonateloaded rats. The regression lines of the data are included (see text). The increase in inulin $\mathrm{TF} / \mathrm{P}$ ratios with tubule length is highly significant $(P$ $<0.01$ ).

(37.3 $\pm 1.7 \mathrm{nl} / \mathrm{min})$ as compared with the control conditions $(42.3 \pm 1.3 \mathrm{nl} / \mathrm{min})$. This was due to the higher $(P<0.001)$ plasma bicarbonate level achieved in low-K rats by the acute load of bicarbonate $(47.2 \pm 40 \mathrm{meq} /$ liter vs. $36.2 \pm 0.7 \mathrm{meq} / \mathrm{liter})$. It is important that in the presence of closely similar early distal bicarbonate loads $(481 \pm 40 \mathrm{pmol} / \mathrm{min}$ in control and $444 \pm 50$ $\mathrm{pmol} / \mathrm{min}$ in $\mathrm{K}$ depletion), distal bicarbonate reabsorption was significantly higher in low-K rats $(247 \pm 17 \mathrm{pmol} / \mathrm{min})$ compared with control rats $(179.4 \pm 18.3 \mathrm{pmol} / \mathrm{min})$. These values are not only significantly different from each other $(P<0.01)$ but both values are also severalfold higher than corresponding values of bicarbonate reabsorption in the non-bicarbonate-loaded conditions. Thus, distal bicarbonate reabsorption in bicarbonateloaded control rats was 3.6 times higher than in nonloaded rats, whereas in low-K rats bicarbonate loading resulted in a 5.4-fold stimulation of bicarbonate transport. Finally, Fig. 5 shows that urinary bicarbonate reabsorption is more complete in $\mathrm{K}$-depleted animals as compared with control rats. In the presence of a significantly higher bicarbonate load in K-depleted rats, the more extensive bicarbonate reabsorption is evidence for overall stimulation of tubular hydrogen ion secretion $(4,5)$.

\section{Discussion}

The present results confirm our previous findings that a significant fraction of filtered bicarbonate is normally reabsorbed along renal cortical distal tubules of the rat kidney (1). We now extended these studies and demonstrated two important properties of distal tubular bicarbonate transport. First, bicarbonate transport can be shown to be load dependent, confirming conclusions previously reached by the measurement of luminal $\mathrm{pH}$ changes in stationary conditions (6). In addition, previous $\mathrm{pH}$ and inulin measurements had also indicated that bicarbonate reabsorption rises during metabolic alkalosis, a condition in which the delivery of bicarbonate out of Henle's loop is sharply increased (7). Some criticism has been directed against the validity of these conclusions because $\mathrm{pH}$ measurements were used to derive bicarbonate concentrations in the collected tubule fluid $(3,8)$. We have now demonstrated by microcalorimetric measurements that the initial conclusions were fully warranted and that load-dependent bicarbonate reabsorption is an important feature of the distal tu-

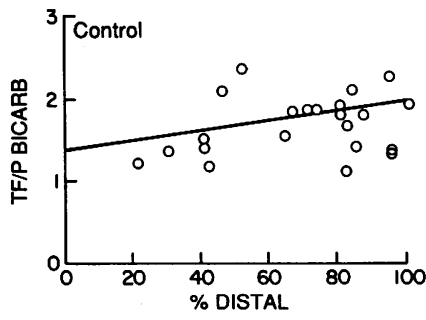

Figure 3. Bicarbonate (total $\mathrm{CO}_{2}$ ) TF/P concentration ratios along distal tubules in control bicarbonate-loaded rats and their regression lines. The correlation between these values and distal tubule length is not significant.

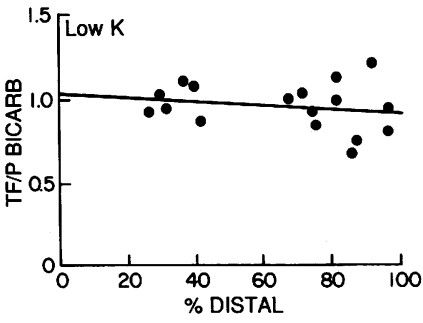

Figure 4. Bicarbonate (total $\mathrm{CO}_{2}$ ) TF/P concentration ratios along distal tubules in low-K bicarbonate-loaded rats and their regression lines. The correlation between these values and distal tubule length is not significant.

bule. The possible reasons why total $\mathrm{CO}_{2}$ reabsorption was not seen in some studies using pump-perfused distal tubules were discussed extensively in another paper (1-3), although it should be noted that Kunau and his associates have demonstrated significant bicarbonate reabsorption in perfused distal rat tubules provided the animals were kept on a high-protein diet (9).

The superficial distal tubule of the rat is made up of several divisions, each composed of different cell types, and the available evidence suggests two mechanisms of acid secretion. Along the thick ascending limb $\mathrm{Na} / \mathrm{H}$ exchange is present $(10,11)$ and its presence in the early distal tubule is possible, whereas sodiumindependent electrogenic $\mathrm{H}^{+}$-ion secretion has been demonstrated to be present in the intercalated cell population found in the initial collecting tubule (late distal tubule) $(12,13)$. Because the initial collecting tubule and cortical collecting tubule are morphologically similar, and bicarbonate secretion occurs in the cortical collecting tubule (14), we were particularly interested in whether the distal tubule shares this functional property. We have not been able to observe bicarbonate secretion in normal acid-base conditions or during either acute metabolic alkalosis or during chronic hypokalemia, a state in which significantly elevated plasma bicarbonate levels were present. If such a process were present it might have been masked by the more massive H-ion secretion.

The observation of load-dependence of bicarbonate transport along the distal tubule is of interest because of significant differences between the distal and proximal tubules. Two features of bicarbonate transport across the proximal tubule are relevant. First, the studies of Malnic et al. (15), Chan et al. (16), Alpern et al. (17), Cogan et al. (18), and Maddox et al. (19) have clearly shown that net bicarbonate reabsorption along the proximal tubule is stimulated by increasing the luminal bicarbonate concentration. Data obtained by the application of the pH-stat technique to the study of acid secretion in the proximal tubule also showed that $\mathrm{H}$-secretion rises proportionately with increasing luminal $\mathrm{pH}$ (20). This behavior conforms to the kinetic properties of the $\mathrm{Na} / \mathrm{H}$ exchanger in the apical cell membrane of proximal tubule cells $(21,22)$. A second feature of bicarbonate transport along the proximal tubule is its strong sensitivity to peritubular

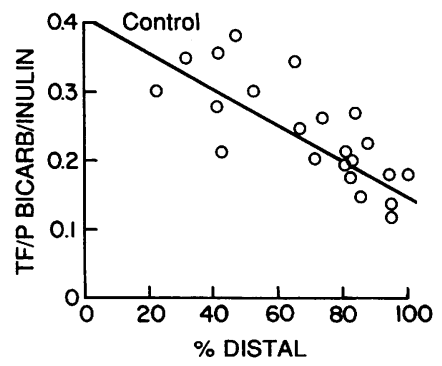

Figure 5. Bicarbonate/inulin TF/P concentration ratios along distal tubules in control bicarbonate-loaded rats and their regression lines. The decrease of these ratios with distal tubule length is highly signifcant $(P<0.01)$. 


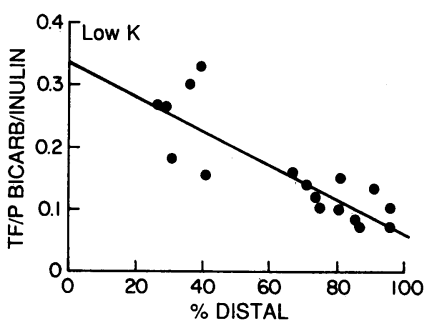

Figure 6. Bicarbonate/inulin $\mathrm{TF} / \mathrm{P}$ concentration ratios along distal tubules in low-K bicarbonate-loaded rats and their regression lines. The decrease of these ratios with distal tubule length is highly significant $(P<0.01)$.

bicarbonate concentration. At a given bicarbonate concentration in the lumen, transport is sharply depressed after elevation of peritubular bicarbonate concentration $(16,23)$. The most likely explanation for this phenomenon is the inhibition of base exit across the basolateral membrane with increasing alkalinity in the peritubular capillaries (24-27).

A comparison of proximal and distal tubule segments indicates relative insensitivity of the distal bicarbonate transport system to peritubular alkalinization. A comparison of proximal distal transport rates of bicarbonate is summarized in Table III. Important differences are apparent. Inspection of Table III shows that during luminal perfusion at a mean bicarbonate concentration of $45 \mathrm{mM}$, bicarbonate reabsorption by proximal tubule was $201 \mathrm{pmol} / \mathrm{min} \cdot \mathrm{mm}$ (17). This value is of similar magnitude to that of our bicarbonate-loaded control animals. This contrasts sharply with the behavior of the proximal tubule during bicarbonate loading, in which at elevated luminal bicarbonate concentration, net bicarbonate reabsorption was only $64 \mathrm{pmol} /$ $\mathrm{min} \cdot \mathrm{mm}$ when the blood bicarbonate was elevated. Jacobson has recently evaluated the effects of elevation of peritubular bicarbonate, from 25 to $50 \mathrm{mM}$, upon net bicarbonate absorption, in the medullary collecting duct (28). He observed a $30 \%$ reduction in reabsorption, a value much less than the $70 \%$ inhibition in the proximal tubule, which resulted from a smaller increment in peritubular bicarbonate (29). Thus, we conclude that the distal nephron continues bicarbonate reabsorption at an elevated rate despite a very significant systemic alkalosis.

At present, it is not clear which features of distal tubule bicarbonate transport are responsible for its insensitivity to peritubular alkalinization. In principle, three properties of $\mathrm{HCO}_{3}^{-}$ reabsorption could be involved. First, it is possible that $\mathrm{H}$-ion secretion across the apical membrane, perhaps by ATP-driven electrogenic $\mathrm{H}$ extrusion, is less sensitive to cellular alkalinization likely to occur during alkalosis induced by acute bicarbonate loading. It is relevant that the process of $\mathrm{H}^{+}$secretion in the proximal tubule is subject to modulation by the amplifying effect of $\mathrm{H}$ on an intracellular modifier site that regulates $\mathrm{Na} / \mathrm{H}$ ex-

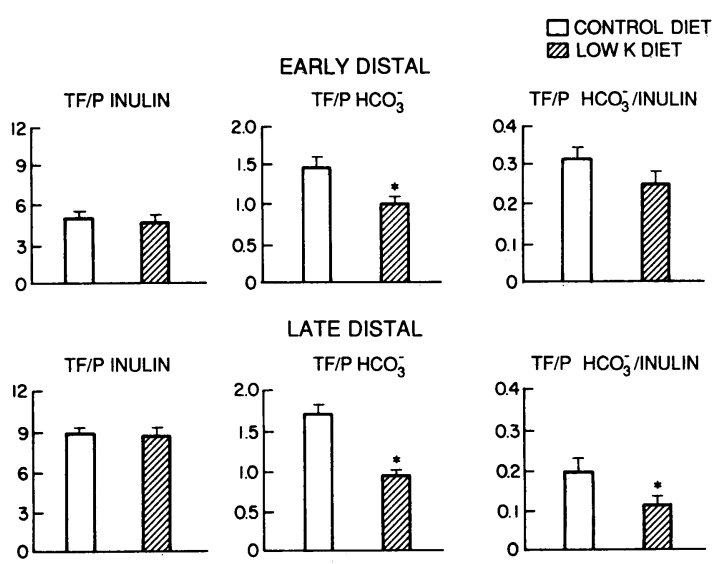

Figure 7. Summary of mean inulin TF/P, bicarbonate TF/P, and bicarbonate/inulin TF/ $\mathrm{P}$ concentration ratios in early and late distal puncture sites in normal and low-K bicarbonate-loaded rats. *Significant difference with respective control $(P<0.005)$.

change independent of the electrochemical gradients of $\mathrm{Na}^{+}$and $\mathrm{H}^{+}$(30). Conceivably, the absence of such a mechanism in distal tubule cells, perhaps intercalated cells, could make the latter less sensitive to systemic acid-base changes.

Second, it cannot be excluded that basolateral bicarbonate extrusion, probably by $\mathrm{HCO}_{3}^{-} / \mathrm{Cl}^{-}$exchange (31), may also be less sensitive to the opposing bicarbonate gradient than its proximal counterpart, the $\mathrm{Na}^{+} / \mathrm{HCO}_{3}^{-}$cotransport system. Such a mechanism would protect and stabilize cell $\mathrm{pH}$ and permit stimulation of bicarbonate transport to occur with the increase in luminal bicarbonate delivery.

Third, it should also be considered that the lower intrinsic bicarbonate permeability of the distal tubule compared with that of the proximal tubule could render proton secretion insensitive to high peritubular bicarbonate. By curtailing backflux of bicarbonate ions from the peritubular capillaries into the tubule lumen, acidification would continue relatively undiminished even during metabolic alkalosis.

It is of interest that bicarbonate loading also has no inhibitory effect on hydrogen ion secretion in the turtle, a preparation sharing many essential features with the mammalian distal nephron $(32,33)$.

Bicarbonate transport during hypokalemia. In our previous studies we noted that fractional distal bicarbonate reabsorption was markedly increased in hypokalemic rats at a time when the deliyery of bicarbonate into the early distal tubule was decreased. The more effective retrieval of bicarbonate in potassium deple-

Table II. Summary of Micropuncture Data in Control and Low-K Rats

\begin{tabular}{|c|c|c|c|c|c|c|}
\hline & \multicolumn{2}{|l|}{ TF/P inulin } & \multicolumn{2}{|l|}{$\mathrm{TF} / \mathrm{P} \mathrm{HCO}_{3}^{-}$} & \multicolumn{2}{|l|}{$\mathrm{TF} / \mathrm{P} \mathrm{HCO}_{3}^{-} /$inulin } \\
\hline & Control & Low $\mathrm{K}$ & Control & Low $\mathrm{K}$ & Control & Low $\mathrm{K}$ \\
\hline Early distal & $4.70 \pm 0.34(6)$ & $4.24 \pm 0.42(6)$ & $1.459 \pm 0.135(6)$ & $1.00 \pm 0.04^{*}(6)$ & $0.314 \pm 0.025(6)$ & $0.250 \pm 0.028(6)$ \\
\hline Late distal & $9.06 \pm 0.45(14)$ & $8.76 \pm 0.45(11)$ & $1.742 \pm 0.086(14)$ & $0.946 \pm 0.049 *(11)$ & $0.197 \pm 0.012(14)$ & $0.112 \pm 0.001 *(11)$ \\
\hline
\end{tabular}

* $P<0.005$ vs. control. (n) Number of tubules. 


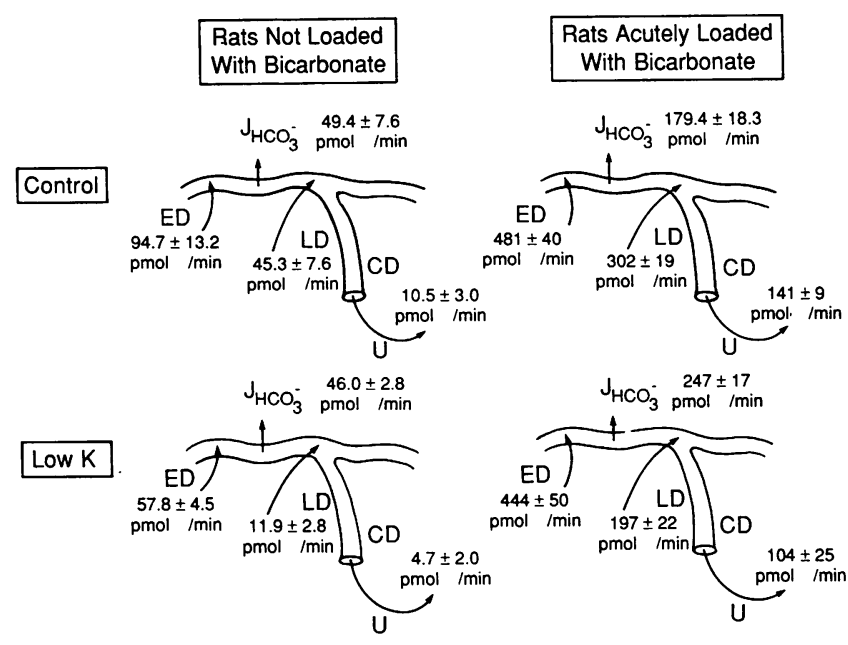

Figure 8. Schematic summary of bicarbonate reabsorption along the nephron in control and low-K rats, loaded and not loaded with bicarbonate. Early distal $(E D)$, late distal $(L D)$, and urine $(U)$ values represent delivery of bicarbonate to these sites. The difference between early and late bicarbonate delivery in both control and low-potassium animals is statistically significant $(P<0.001$ in all conditions). Data for nonloaded rats from reference 1 .

tion in the presence of a higher transepithelial bicarbonate gradient is strong evidence for stimulation of proton secretion in this experimental setting. However, we could not exclude the possibility that bicarbonate reabsorption might have been more complete because of the reduced bicarbonate load. In our present experiments we were able to circumvent this problem. We show that, at very similar distal delivery rates of bicarbonate achieved by bicarbonate loading, distal tubules in hypokalemia reabsorbed roughly $40 \%$ more bicarbonate than control rats. Accordingly, we conclude that the distal tubule has a significant role in the maintenance of the state of metabolic alkalosis of $\mathrm{K}$ depletion, which we uniformly observed in our experimental setting.

Although direct cell pH measurements have not yet been done in cells of the distal tubule, it is possible that cell acidification, postulated to occur in tubule cells during hypokalemia, may be responsible for enhanced bicarbonate transport $(16,34)$.

Physiological role of cortical distal tubule. The present studies permit a quantitative evaluation of the physiological role of the

Table III. H-Ion Secretion in Rat Cortical Nephron in Control and Alkalotic Conditions

\begin{tabular}{|c|c|c|c|c|}
\hline \multirow[b]{2}{*}{ Segment } & \multirow[b]{2}{*}{$\begin{array}{l}\text { Experimental } \\
\text { condition }\end{array}$} & \multicolumn{2}{|l|}{$\mathrm{HCO}_{3}$} & \multirow[b]{2}{*}{$J_{\mathbf{H}}$} \\
\hline & & $\begin{array}{l}\text { Mean luminal } \\
\text { concentration }\end{array}$ & $\begin{array}{l}\text { Mean capillary } \\
\text { concentration }\end{array}$ & \\
\hline & & $m m$ & $m m$ & $\mathrm{pmol} / \mathrm{min} \cdot \mathrm{mm}$ \\
\hline Proximal & Control & 45.4 & 24.0 & $201^{*}$ \\
\hline Proximal & Acute alkalosis & 39.3 & 37.1 & $64^{\ddagger}$ \\
\hline Distal ${ }^{8}$ & Acute alkalosis & 57.9 & 36.2 & 179 \\
\hline Distal $^{5}$ & Low $\mathbf{K}$ & 45.9 & 47.2 & 247 \\
\hline
\end{tabular}

* From reference 17.

* From reference 28.

Data are per distal tubule, but because perfused length averaged $\sim 1$ $\mathrm{mm}$ they are comparable with proximal values. distal tubule in the overall process of bicarbonate reabsorption. Whereas the bulk of bicarbonate transport occurs along the proximal tubule, the distal tubule reabsorbs a modest but significant fraction of filtered bicarbonate, 5-10\% during normal acid-base conditions, an amount equal to or larger than that assigned to the cortical and medullary collecting tubule $(7,35)$. Importantly, distal bicarbonate transport is normally unsaturated, as evidenced by the striking increase of transport that takes place when distal delivery increases. Under such conditions, fractional reabsorption may almost triple. The capacity for increased bicarbonate reabsorption manifests itself also during hypokalemia, in which the distal tubule contributes to high bicarbonate levels in the blood by sharply stimulated $\mathrm{H}$-ion secretion. Finally, in contrast to the proximal tubule, high transport rates of bicarbonate are maintained despite systemic alkalosis, a condition known to depress bicarbonate transport in the proximal tubule.

\section{Acknowledgments}

This research was supported by National Institutes of Health grant AM17433.

\section{References}

1. Capasso, G., R. Kinne, G. Malnic, and G. Giebisch. 1986. Renal bicarbonate reabsorption in the rat. I. Effects of hypokalemia and carbonic anhydrase. J. Clin. Invest. 78:1558-1567.

2. Lucci, M. S., L. R. Pucacco, N. W. Carter, and T. D. DuBose. 1982. Evaluation of bicarbonate transport in rat distal tubule: effects of acid-base status. Am. J. Physiol. 238:F372-F379.

3. Levine, D. Z. 1985. An in vivo microperfusion study of distal tubule bicarbonate reabsorption in normal and ammonium chloride rats. J. Clin. Invest. 75:588-595.

4. Jacobson, H. R., and W. H. Seldin. 1984. On the generation, maintenance and correction of metabolic alkalosis. Am. J. Physiol. 245: F425-F432.

5. Luke, R. G., and J. H. Galla. 1983. Chloride depletion alkalosis with normal extracellular fluid volume. Am. J. Physiol. 245:F419-F424.

6. Giebisch, G., G. Malnic, G. B. Mello, and M. Mello-Aires. 1977. Kinetics of luminal acidification in cortical tubules of the rat kidney. $J$. Physiol. 267:571-600.

7. Malnic, G., M. Mello-Aires, and G. Giebisch. 1972. Micropuncture study of renal tubular hydrogen ion transport in the rat. Am. J. Physiol. 222:147-158.

8. DuBose, T. D., L. R. Pucacco, M. S. Lucci, and R. W. Carter. 1979. Micropuncture determination of $\mathrm{pH}, \mathrm{pCO}_{2}$, and total $\mathrm{CO}_{2}$ concentration in accessible structures of the rat renal cortex. J. Clin. Invest. 64:476-482.

9. Kunau, R. T., Jr., and K. A. Walker. 1987. Total $\mathrm{CO}_{2}$ absorption in the distal tubule of the rat. Am. J. Physiol. 252:F468-F473.

10. Good, D. W. 1985. Sodium-dependent bicarbonate absorption by cortical thick ascending limb of rat kidney. Am. J. Physiol. 248:F821F829.

11. Oberleithner, H. 1985. Intracellular $\mathrm{pH}$ in diluting segment of frog kidney. Pfluegers Arch. Eur. J. Physiol. 404:244-251.

12. Koeppen, B. M., and S. I. Helman. 1982. Acidification of luminal fluid by the rabbit cortical collecting tubule perfused in vitro. Am. J. Physiol. 242:F521-F531.

13. Laski, M. E., and N. A. Kurtzman. 1983. Characterization of acidification in the cortical and medullary collecting tubule of the rabbit. J. Clin. Invest. 72:2050-2059.

14. McKinney, T. D., and M. B. Burg. 1978. Bicarbonate absorption by rabbit cortical collecting tubules in vitro. Am. J. Physiol. 234:F141F145. 
15. Malnic, G., and M. Mello-Aires. 1971. Kinetic study of bicarbonate reabsorption in proximal tubule of the rat. Am. J. Physiol. 220: 1759-1767.

16. Chan, Y. L., B. Biagi, and G. Giebisch. 1982. Control mechanisms of bicarbonate transport across the rat proximal convoluted tubule. Am. J. Physiol. 242:F532-F543.

17. Alpern, R. J., M. G. Cogan, and F. C. Rector. 1982. Effect of luminal bicarbonate concentration on proximal acidification in the rat. Am. J. Physiol. 243:F53-F59.

18. Cogan, M. G., D. A. Maddox, M. S. Lucci, and F. C. Rector. 1979. Control of proximal bicarbonate reabsorption in normal and acidotic rats. J. Clin. Invest. 64:1168-1180.

19. Maddox, D. A., and F. Gennari. 1985. Load-dependence of $\mathrm{HCO}_{3}$ and $\mathrm{H}_{2} \mathrm{O}$ reabsorption in the early proximal tubule of the Munich-Wistar rat. Am. J. Physiol. 248:F113-F121.

20. Malnic, G., M. Mello-Aires, A. C. Cassola, A. G. Lopes, and G. Giebisch. 1984. The pH-stat technique applied to rat proximal tubule. Abstracts of the 8th International Biophysics Congress. Bristol, England. 295.

21. Aronson, P. S. 1983. Mechanism of active $H$ secretion in the proximal tubule. Am. J. Physiol. 245:F647-F659.

22. Murer, H., U. Hopfer, and R. Kinne. 1976. Sodium-proton antiport in brush-border membrane vesicles isolated from rat small intestine and kidney. Biochem. J. 154:597-604.

23. Sasaki, S., C. A. Berry, and F. C. Rector. 1982. Effect of luminal and peritubular $\mathrm{HCO}_{3}^{-}$concentrations and $\mathrm{PCO}_{2}$ on $\mathrm{HCO}_{3}^{-}$reabsorption in rabbit proximal convoluted tubules perfused in vitro. J. Clin. Invest. 70:639-649.

24. Burckhardt, B.-C., K. Kato, and E. Frömter. 1984. Electrophysiological analysis of bicarbonate permeation across the peritubular cell membrane of rat kidney proximal tubule. I. Basic observations. Pfluegers Arch. Eur. J. Physiol. 401:34-42.
25. Boron, W. F., and E. L. Boulpaep. 1983. Intracellular pH regulation in the renal proximal tubule of the salamander. Basolateral $\mathrm{HCO}_{3}$ transport. J. Gen. Physiol. 81:53-94.

26. Alpern, R. J. 1985. Mechanism of basolateral membrane H/OH/ $\mathrm{HCO}_{3}$ transport in the rat proximal convoluted tubule. A sodium coupled electrogenic process. J. Gen. Physiol. 86:613-636.

27. Brisolla-Diuana, A., C. Amorena, and G. Malnic. 1985. Transfer of base across the basolateral membrane of cortical tubules of rat kidney. Pfluegers Arch. Eur. J. Physiol. 405:209-215.

28. Jacobson, H. R. 1984. Medullary collecting duct acidification. Effects of potassium, $\mathrm{HCO}_{3}$ concentration, and $\mathrm{PCO}_{2}$. J. Clin. Invest. 74: 2107-2114.

29. Alpern, R. J., M. G. Cogan, and F. C. Rector, Jr. 1982. Effect of extracellular fluid volume and plasma bicarbonate concentration on proximal acidification in the rat. J. Clin. Invest. 71:1736-1746.

30. Aronson, P. S., J. Nee, and M. A. Suhm. 1982. Modifier role of internal $\mathrm{H}^{+}$in activating the $\mathrm{Na}^{+}-\mathrm{H}^{+}$-exchanger in renal microvillus membrane vesicles. Nature (Lond.). 299:161-163.

31. Stone, D. K., D. W. Seldin, J. P. Kokko, and H. R. Jacobson. 1983. Anion dependence of rabbit medullary collecting duct acidification. J. Clin. Invest. 71:1505-1508.

32. Cohen, L. 1980. $\mathrm{HCO}_{3}-\mathrm{Cl}$ exchange transport in the adaptive response to alkalosis by turtle bladder. Am. J. Physiol. 239:F167-F174.

33. Sabatini, S. 1985. Effect of cyclic AMP on acidification in the isolated turtle bladder. Kidney Int. 27:25-30.

34. Cemerikic, D., C. S. Wilcox, and G. Giebisch. 1982. Intracellular potential and $\mathrm{K}^{+}$activity in rat kidney proximal tubular cells in acidosis and $\mathrm{K}^{+}$depletion. J. Membr. Biol. 69:159-165.

35. Warnock, D. G., and F. C. Rector. 1981. Renal acidification mechanisms. In The Kidney. 2nd ed. B. M. Brenner and F. C. Rector, Jr., editors. W. B. Saunders Co., Philadelphia. 440-494. 